\title{
Fuzzy and Genetic Algorithm-based Decision-making Approach for Collaborative Team Formation: A Study on User Acceptance using UTAUT
}

\author{
Azleena Mohd Kassim ${ }^{1}$, Norhanizah Minin², Yu-N Cheah ${ }^{3}$, Fazilah Othman ${ }^{4}$ \\ School of Computer Sciences, Universiti Sains Malaysia, 11800 Penang, Malaysia ${ }^{1,2,3}$ \\ Anti-Doping Laboratory Qatar, PO Box 27775, Doha, State of Qatar ${ }^{4}$
}

\begin{abstract}
Forming an optimal collaborative team is achieved using members characteristics to improve team efficiency. A team's performance may have a negative effect when a team is formed randomly. Moreover, it is quite impossible to achieve an optimal team manually as the formation can expand into countless possibilities. Hence, this paper presents a decisionmaking framework for collaborative team formation by incorporating Fuzzy Logic and Genetic Algorithm (Fuzzy-GA). The framework has been initiated by combining effective team formation factors such as skills, trust, leadership, and individual performance. Unified Theory of Acceptance and Use of Technology (UTAUT) is utilised to survey the readiness and technology acceptance of the organisations' employees in adopting the proposed decision-making approach to form a collaborative team. The UTAUT survey had proven that behavioural intention (BI) had a positive impact on the performance expectancy (PE), effort expectancy (EE), social influence (SI) and facilitating conditions (FC). However, behavioural intention (BI) had a negative impact on the voluntariness of use (VU); thus the transformation of collaborative team formation must be further explored to increase the team's voluntarism towards this automated collaborative team formation.
\end{abstract}

Keywords-Collaborative team formation; genetic algorithm; fuzzy logic; unified theory of acceptance and use of technology (UTAUT)

\section{INTRODUCTION}

It is important to have an effective team in an organisation, particularly where there is an issue with the operating costs. Hence, an organisation needs to enforce the team development model for developing an effective team [1,2]. A team must work together to accomplish organisational activities, share common goals and interact socially [3].

A collaborative team comprises people with a variety of skills to execute a task collaboratively, where they are able to share the resources, information, and cost to deliver optimal outcomes [4]. Positive outcomes can be reached when the team members incorporate their knowledge, work well together, and welcome feedback. It has been shown that team performance exceeded the efficiency of two self-employed people [2,5]. This indicated the importance of communication and collaboration between team members. Bahrami et al. [6] also stated that accuracy in a collaborative team is higher because the team's precision is higher than that of the individuals.
An organisation consists of employees with diverse expertise, knowledge, and experience. An efficient team can enhance the team's innovativeness. Thus, for a collaborative task to be implemented efficiently, selecting team members of a collaborative team is a crucial process. [7] stated that the problem in the collaborative team formation using the decision-making approach in selecting the team members is that they are not always strategic and do not give the best output as cost and time play a big role. Hence, numerous research was executed to ascertain the effective decision support approach to form a collaborative team in an organisation. However, not much of the research focused on studying the acceptance towards the collaborative team formation technology.

This research is supported by the Short-Term Grant, Universiti Sains Malaysia (304/PKOMP/6315392).

Thus, this paper aims to study the acceptance of the proposed fuzzy and genetic algorithm-based (Fuzzy-FA) decision-making approach of collaborative team formation. To achieve this aim, the objectives of this paper are 1) to outline the combinations of factors for the decision-making system to form a collaborative team, 2) to propose a framework of a decision-making system by using Fuzzy Logic (FL) and Genetic Algorithm (GA) and 3) to evaluate the acceptance by using the Unified Theory of Acceptance and Use of Technology (UTAUT) survey.

In the next section of this paper, the related works relevant to collaborative work are presented. Subsequently, Section III highlights the framework of the collaborative team formation by finalising the team formation factors and combining the FL approach and GA (Fuzzy-GA). Section IV explains further the details of the proposed Fuzzy-GA. Section V focuses on the user acceptance survey development of the proposed FuzzyGA. Section VI presents the results from the UTAUT survey, which was used to evaluate the users' acceptance of the proposed framework. Section VII provides a conclusion to the paper.

\section{RELATED WORK}

Leadership and trust were identified as factors for a team to have a high performance, where leadership was identified to have a direct influence on team performance, whereas trust could facilitate the leadership impacts [8]. Trust was reported to be an important factor to be considered in team formation 
$[9,10]$. These findings showed that trust is an essential factor in establishing a collaborative team and sustaining the whole team. Zhang and Zhang [11] reported that team trust was a good predictor; thus, establishing trustworthy relationships in teams would lead to improved performance.

Skill was another crucial factor in team formation [12,13] where this factor indicated the workability of the people in the team [13]. Without the proper selection of team members with the right skills, the project to be executed might face failure and, at the same time, waste the organisational resources [12]. Fathian et al. [12] recommended three key factors: skills, collaboration network, and reliability for their proposed team formation optimisation model. These three factors were proven to support and enhance collaborative work in the context of team formation.

Knowledge was recognised as one of the key factors that could positively influence team effectiveness [14]. The knowledge factor would always greatly influence individual performance by measuring working experiences and capability [15]. Furthermore, [14] claimed that factors like leadership, management support, team diversity, reward, and goal clarity would directly affect team efficacy. A reasonable human resource allocation framework was presented with the assignment of human resources for multiple teams formation [16]. However, the optimisation approach utilised was not mentioned, and the limitation was that it did not include important human-related factors such as individual performance.

The genetic algorithm (GA) approach has been widely used in some works related to team or group formation. The Bayesian Network-based Team Formation (BN-TF) was utilised to develop a team in the setting of a business process by applying the problem as a Most Probable Explanation (MPE) [17]. GA was applied with some modifications where the Forward-Backward Greedy GA was developed as the outcome. Two factors were used: handover relation and individual expertise, but the tool to define the degree of these factors were not available.

To assist managers in multiple projects team formation, GA was utilised as a decision-making tool by using the group cohesion factor [18]. The GA showed near-optimal results, which was achieved in a short processing time. Nonetheless, when multiple combinations of employee skills were used, this approach was reported as unsuitable for forming teams dynamically. The decision support system was developed by utilising the fuzzy descriptors to assist the requirement specifications based on the team members' skills [19]. Then, the fuzzy criteria were optimised using GA, and the outcome proved that the decision support system was computationally efficient. Although it was reported to be practical, however, they did not put priority on choosing employees that have high rating values. Moreover, [19] only focused on one factor in team formation: the skills factor.

Silva and Krohling [20] proposed an algorithm based on sociometry to form a team with the human resource as the main factor, by using the fuzzy numbers approach to maximise cohesion. The algorithm allowed the expression of personal preferences provided to the sociometric test. The study reported a promising result where project managers were found to have the potential in using the algorithm as a decisionmaking tool; however, they overlooked the skills factor. Another limitation was that the part-time employees from the employee database were not considered to be assigned to a group formation. Based on some previous research $[8,9,10]$, the decision-making approach is an important criterion in forming a collaborative team, and many decision-making approaches were discovered.

One of the well-known theories for user acceptance is known as the Technology Acceptance Model (TAM) [21] and further extended by the researchers [22]. Davis et al. [22] suggested two important variables toward the usage of computers: perceived usefulness and perceived use. These two variables are seen as the main variables to affect the results of the user acceptance indirectly or directly [23]. The Unified Theory of Acceptance and Use of Technology (UTAUT) model is another well-known theory used in the study for acceptance and adoption of technology [24]. In comparison to TAM, UTAUT is considered to have a clearer objective to assess the acceptance of technology from the users' point of view [25]. Venkatesh et al. [26] reported that UTAUT performed better than other models in terms of $70 \%$ variance in behavioural intention.

UTAUT illustrates a set of factors that influence the user behaviour of acceptance and the behavioural intention towards an information system: Performance Expectancy (PE), Effort Expectancy (EE), Social Influence (SI) and Facilitating Conditions (FC) [14]. Besides that, the UTAUT model recognises four moderators, which influences the relationships between these constructs: Age, Gender, Voluntariness of Use, and Experience. UTAUT was utilised to analyse the proposal for introducing an e-mobile payment service targeted at Brazilian mobile phone users [27], whereas another study employed UTAUT to validate the acceptance of online games [28]. UTAUT was used to evaluate an electronic health record system by looking into factors impacting users' intention to use the system [29]. Howard et al. [30] extended the UTAUT model to further understand the perceptions towards working with building information modelling (BIM). Howard et al. [30] utilised the moderators of experience and voluntariness and, from the results, implied that there was a need to relook at the policies to improve the acceptance towards the BIM.

\section{Proposed Collaborative TEAm Formation}

\section{A. Factors in the Collaborative Team Formation}

The identification process and critical evaluations are important for improving the team development process. For the team formation problem, there are a lot of different factors that can be taken into account, where the factors may or may not directly influence the efficacy of the team formed [8]. Table I shows the factors that were identified in some related works. Trust, skills and leadership are important factors in forming a collaborative team to improve team efficiency in organisations. Hence, these three main factors are adopted and incorporated together in this work. 
TABLE I. FACTORS IDENTIFIED FOR TEAM FORMATION

\begin{tabular}{|l|l|}
\hline Factors & Type of Team and Reference \\
\hline Leadership and Trust & Exhibitor team [8] \\
\hline Trust & Virtual team [9] \\
\hline Trust & Global virtual team [10] \\
\hline $\begin{array}{l}\text { Skill, reliability, and collaboration } \\
\text { network }\end{array}$ & Cross-funtional team [11] \\
\hline $\begin{array}{l}\text { Skill, leadership, reward, management } \\
\text { support, team diversity and goal clarity }\end{array}$ & Technical project team [14] \\
\hline Human resource allocation & General team formation [16] \\
\hline
\end{tabular}

The factors, collaboration network and reliability by [11], together with management support, reward, team diversity and goal clarity by [14] were not included in this proposed work as those factors are related to the group as a whole, whereas the focus on this work at this stage is to leverage on the strength of each individual's factor as a contribution to the group formation. Human resources were assigned to form multiple teams but did not focus on individual performance, which was the limitation of the work by [16]. Thus, individual performance is included in this proposed work as it was considered an important factor related to individuals that contributed to a group's efficiency [16].

As a result, together with the three important factors: skills, trust, and leadership, individual performance is included as the fourth factor for the proposed team formation framework. This research presented in this paper consolidates all these four important factors while designing an effective decision-making approach to form a collaborative team.

\section{B. The Decision-making Approach}

A systematic and accurate decision-making approach to form an effective collaborative team is important to improve team effectiveness. The combination of FL and GA enhances collaborative work in team formation and is based on previous research [19]. FL was shown by [19] as a powerful tool in classifying the imprecise input from skill factor with the manipulation of the FL number (where the process of fuzzification generates the fuzzy set values - between 0.0 and 1.0 in a fuzzy set, denoting different levels or degrees). Meanwhile, GA has been used as an optimisation method for determining the best fitness result in fuzzy criteria.

1) Fuzzy Logic (FL): Extended from a classical set theory, FL handles problems with ambiguous and imprecise data [31]. There are 3 FL concepts 1) Fuzzy set, which allows the FL to set some boundaries, 2) Fuzzy set describes variables with values generated by linguistic variables, and 3) Constraints on the value linguistic variable values by fuzzy set assignment based on distributions of possibility [32]. Before the implementation takes place in the real world, the fuzzy approach supports ambiguity and can be assessed repetitively [33].

2) Genetic Algorithm (GA): GA is one popular approach to solving optimisation problems [34]. Motivated by the natural selection process, GA is seen to be very efficient in solving real-world problems. For example, mixed-integer programming is one of the problems that can be solved using GA [35]. The fitness level is calculated based on the required criteria of the problems' desired requirements. The phases in GA include 1) the initialisation of the population, 2) evaluation of the fitness value, 3) selection, where better results are reported to be achieved with a good selection strategy [36], 4) crossover - a process of recombining parents to have a chance of producing better individuals [37], 5) mutation - an operator that helps to bring some genetic diversity to the chromosome produced [34], 6) repetition of the new population until the best fitness value has been met or the termination criteria achieved.

\section{Fuzzy-GA Approach for the Collaborative Team Formation}

The proposed collaborative team formation has the FL and GA components, which was also used in the model presented by [19]. However, this proposed work is different and extended in terms of 1) determination of the pool of employees, 2) suitable employees are chosen with high rating values, 3) incorporating more factors related to team efficiency, in the team formation.

In this study, the four factors (skills, trust, leadership, and individual performance) were accessed from the employee database, and the fuzzy value properties were derived for each factor. Fig. 1 shows the framework of the proposed decisionmaking approach, using the FL and GA (Fuzzy-GA). In the project requirements, the inputs may seem to be imprecise; thus, using FL can attain a more robust solution.

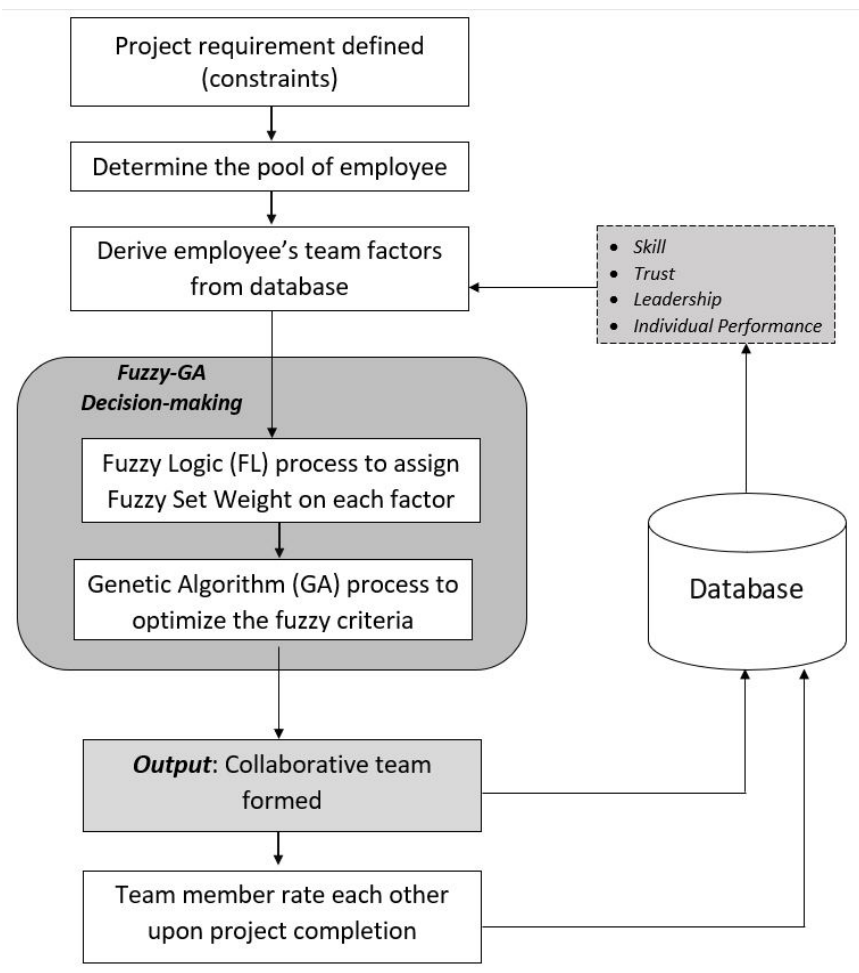

Fig. 1. The Framework of the Fuzzy-GA Decision-making Approach. 
First, FL would generate the fuzzy criteria for the factors extracted. Then, the GA would formulate the fuzzy criteria into a fitness value calculation and optimise the solution to form the team. Upon the team formation and completion, the team members would be allowed to rate their other team members based on the skills, trust, leadership and individual performance factors.

\section{Fuzzy Evaluation Weight}

The selection of team members depended on certain project requirements. Project requirements usually contain ambiguous terms like high, low, medium, easy, or maximum. In this case, FL could help to interpret the ambiguous terms. The method to assign the weight of the fuzzy evaluation is shown in Fig. 2, where the FL approach focused on checking and defining membership set and fuzzy set. This definition is based on trust, skill, leadership, and individual performance factors.

A fuzzy number is derived from a fuzzy membership function $\mathrm{A}: \mathrm{R} \rightarrow[0,1]$, where $\mathrm{A}$ has at least a real number in the set of numbers, R; and the elements in $\mathrm{R}$ are mapped to the value between 0 and 1 [38]. Thus, to assign the fuzzy number, it needs to be represented by membership sets. The author in [39] utilised the same distribution of fuzzy sets (low, medium and high) for the membership functions, whereas [40] used three fuzzy sets (small, medium, large) in their work. Biswas and Ghosh [41] explained that the fuzzification process can be done by allocating the triangular form of membership functions and that this triangular form is the simplest approach. [41] applied the three linguistic fuzzy sets- which were low, medium and high, as the input parameters and they were equally spaced to make use of the entire input spaces.

In this study, the membership set was categorised as high, medium and low for each factor, as previous researchers [39, $40,41]$ had recommended this range to simplify the solution. Table II presents the fuzzy sets for each membership set, for each type of factor, respectively. Each factor had its rating, whether based on category or a range of values, to be categorised into the different membership sets, as shown in Table II. Based on the membership set, the fuzzy set weight was assigned, where value 1.0 was assigned for "high", value 0.5 was assigned for "medium", and value 0.1 was assigned for "low".

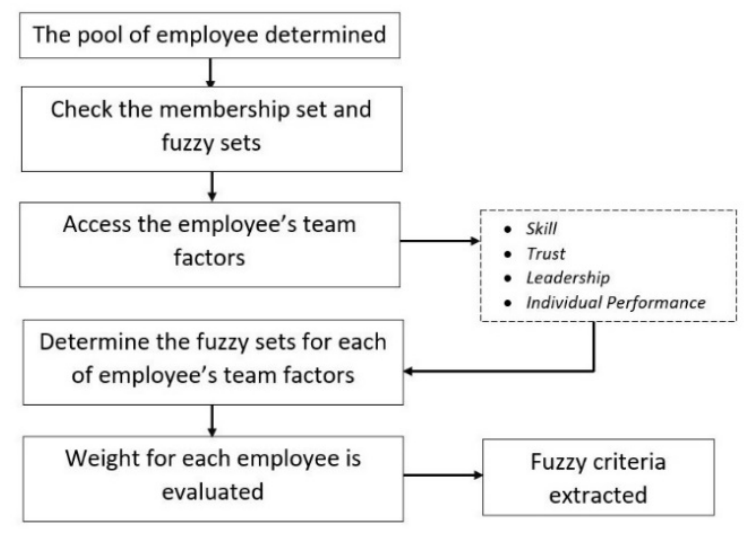

Fig. 2. The Assignment of Fuzzy Evaluation Weight.
TABLE II. FUZZY SETS AND MEMBERSHIP SETS

\begin{tabular}{|l|l|l|l|}
\hline Factors & $\begin{array}{l}\text { Rating } \\
\text { (category/value } \\
\text { range) }\end{array}$ & $\begin{array}{l}\text { Membership } \\
\text { Sets }\end{array}$ & $\begin{array}{l}\text { Fuzzy } \\
\text { Sets } \\
\text { Weight }\end{array}$ \\
\hline \multirow{3}{*}{ Skills } & Expert & High & 1.0 \\
& Intermediate & Medium & 0.5 \\
& Beginner & Low & 0.1 \\
\hline \multirow{3}{*}{ Trust } & $8-10$ & High & 1.0 \\
& $4-7$ & Medium & 0.5 \\
\hline \multirow{3}{*}{ Leadership } & $0-3$ & Low & 0.1 \\
& $8-10$ & High & 1.0 \\
\hline \multirow{2}{*}{ Individual } & $4-7$ & Medium & 0.5 \\
Performance & $0-3$ & Low & 0.1 \\
\hline & $8-10$ & High & 1.0 \\
& $4-7$ & Medium & 0.5 \\
\hline
\end{tabular}

The detailed steps are shown in the pseudocode, as shown in Fig. 3. The project requirements were filtered, and the suitable employee with their rating from the database was determined for each of the four-team factors, $f_{1}$ to $f_{4}$ (skills, trust, leadership, and individual performance). The steps in FL can be seen from lines 6 to 12 . The process continues with the GA approach, which is explained further in the next section.

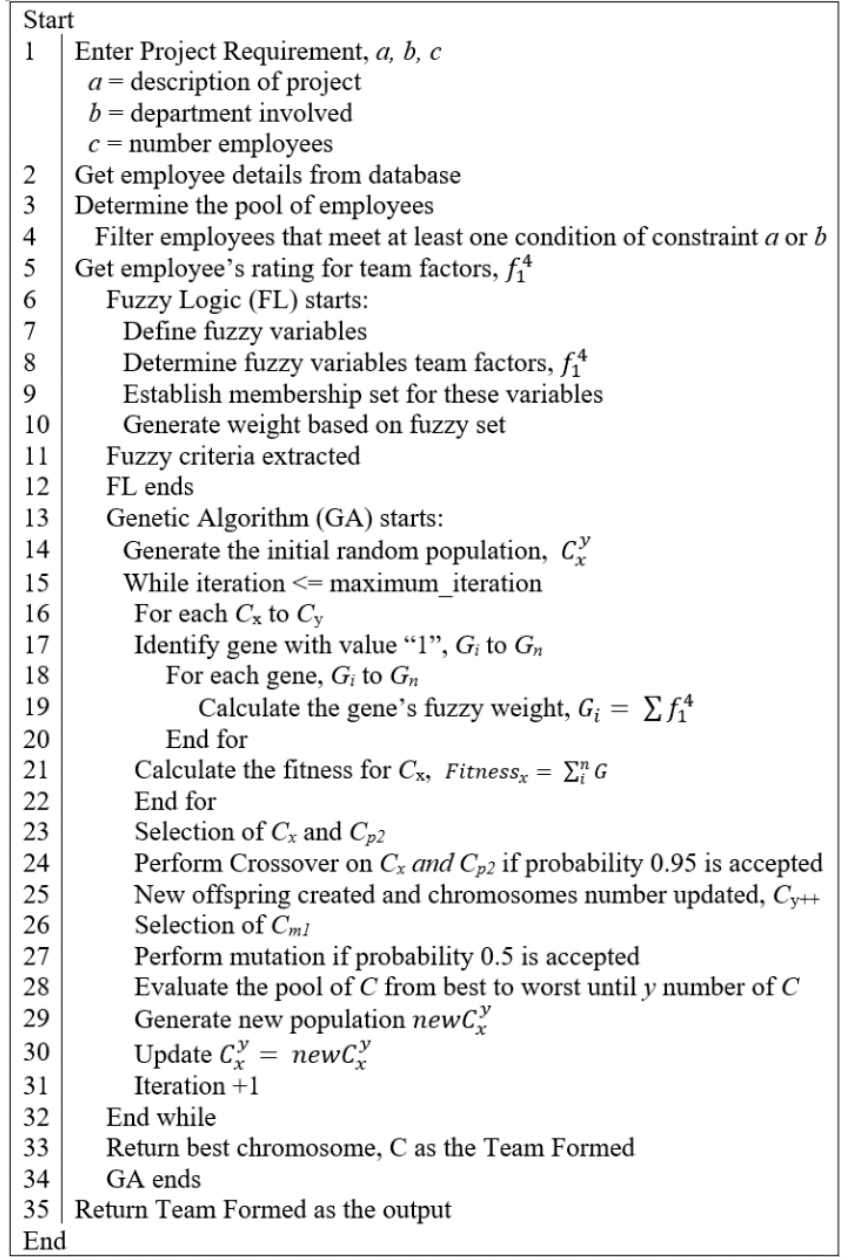

Fig. 3. The Fuzzy-GA Pseudocode for the Team Formation. 


\section{E. Optimisation of Fuzzy Criteria using GA}

After the FL has generated weights for the four factors based on a fuzzy set using the employee's rating database, the GA would then generate the population of parents as chromosomes. The steps in GA are shown in the pseudocode in Fig. 3 from lines 13 to 34 .

For the initial population, $y$ number of parent chromosomes, $C$ were randomly generated. For this study, $y=$ 100 , which means there were 100 parent chromosomes, $C$ in each generation (iteration). The solution representation of each $y$ chromosome, $C$ consists of genes of individuals, $G$, where the number of the individuals were based on the number of employees available in the database.

For example, if there are 10 employees, then the size of each chromosome is 10 genes (individuals). Based on the requirements set during the constraint requirement, the number of people formed into a group, $c$, was pre-determined. Thus, during the initial population, the number of genes to be assigned to a group was based on the set constraint. In the solution representation, the genes in the chromosome assigned with value " 1 " indicate that they were assigned to the group, whereas values " 0 " indicate that they do not belong. Thus, $n$ number of genes, $G$, was assigned with value " 1 ", indicating that there was $n$ number of people to be formed into a team.

For example, in the constraint requirement, if the number of people in a group was set to 5 , then 5 genes in the chromosome would be randomly assigned with value " 1 " while others were assigned with value "0". Fig. 4 shows the example of the chromosome representation for the requirements of 5 people to be formed in a group, with 10 people available for the group formation (individuals labelled as A to J). In this example, in the current solution, individual (gene) C, E, G, I and J were assigned with value " 1 " denoting that they were selected to be in the current group formation.

\begin{tabular}{|l|l|l|l|l|l|l|l|l|l|} 
A & B & C & D & E & F & G & H & I & J \\
\hline 0 & 0 & 1 & 0 & 1 & 0 & 1 & 0 & 1 & 1 \\
\hline
\end{tabular}

Fig. 4. Example of Chromosome Structure for the Solution Representation.

The fitness value of the current chromosome solution (parent) would be calculated based on the genes assigned to value " 1 " in the current solution. The fitness calculation for the $i$-th individual gene assigned to value " 1 ", $G_{i}$, is shown in Equation (1). The fuzzy weight values generated based on fuzzy set for each factor, $f_{1}$ to $f_{4}$ (skill, trust, leadership and individual performance) for the $i$-th individual, are added as the total weight for the $G_{i}$. Assume that there was $n$ number of people set to be in the group formation in the constraint requirement. Therefore, there would be $n$ number of people to be assigned with the value "1". The overall fitness value for the current solution, $x$, $\left(\right.$ Fitness $\left._{x}\right)$ would be calculated, where the gene values from individual ${ }_{i}$ to individual $_{n}$ were summed together, as shown in Equation (2).

$G_{i}=\sum f_{1}^{4}$

Fitness $s_{x}=\sum_{i}^{n} G$
Then, GA would proceed with the crossover and mutation process to produce new offspring from the pool of parents. A high crossover rate is usually used as it was reported to have good results on the optimisation process. Following the suggestions by [42] and [43], a crossover rate of 0.95 was applied. For the mutation rate, the suggested value of 0.5 by [44] was adopted as this was reported to have a better solution quality. Thus, crossover and mutation were implemented, and then fitness was calculated again for the newly formed offsprings and parents. The new generation was produced with a selection of 100 chromosomes with the best fitness values, replacing the 100 parent chromosomes in the previous generation. This process was repeated until the highest fitness score was converged or reached the stopping criterion. Finally, a group was formed with the best fitness value and produced as an output of the collaborative team formation.

\section{User AcCePtance SuRVEy on the Proposed COLLABORATIVE TEAM FORMATION}

This section presents the development of the case study, the Unified Theory of Acceptance and Use of Technology (UTAUT) framework, and the data collection details. The case study was created to produce an artefact to be evaluated by the respondents. To evaluate the user acceptance, a survey was carried out, and the UTAUT model was used. Thus, the details of the framework and the hypothesis created are presented in this section.

\section{A. Development of the Case Study}

To study the user acceptance of this framework, a case study was constructed based on the team formation with the requirements of five employees to complete a project. The case study for this proposed framework was on the collaborative team formation in IT Department that required experts with a specification in UNIX server programming. The rules were defined for extraction using the standard format for project requirements. While this example was drawn from the IT department of an organisation, a similar practice can extend to all kinds of organisations with different project member requirements. This case study was built to be used as an artefact in the survey of user acceptance using the UTAUT questionnaire.

In this case study, the project required people who have skills in UNIX programming. The employee's database had already been assigned with values in the four factors of the Fuzzy-GA collaborative team formation. The four factors were derived for the FL process. From the rating values of the employees for each factor, FL generated the final weight using the membership set and fuzzy set. The case study followed the Fuzzy-GA collaborative team formation steps as presented in Section III. The example of this case study was developed as a prototype and produced as an artefact to be evaluated using the UTAUT survey for user acceptance.

\section{B. Development of Unified Theory of Acceptance Framework}

UTAUT is an acceptance model that justifies the information system's usage and intention by the user [24]. The proposed framework in this research was validated based on UTUAT model using a questionnaire survey method. Fig. 5 shows the framework of the user acceptance model proposed in 
this study. Six variables were involved, with the primary variable being the dependent variable, the Behavioural Intention (BI). BI variable denotes a person's intention to use technology, and in this case - the intention to use the FuzzyGA collaborative team formation system. The UTAUT framework proposed in this study predicted that BI could be influenced by four independent variables: Performance Expectancy (PE), Effort Expectancy (EE), Social Influence (SI) and Facilitating Conditions (FC).

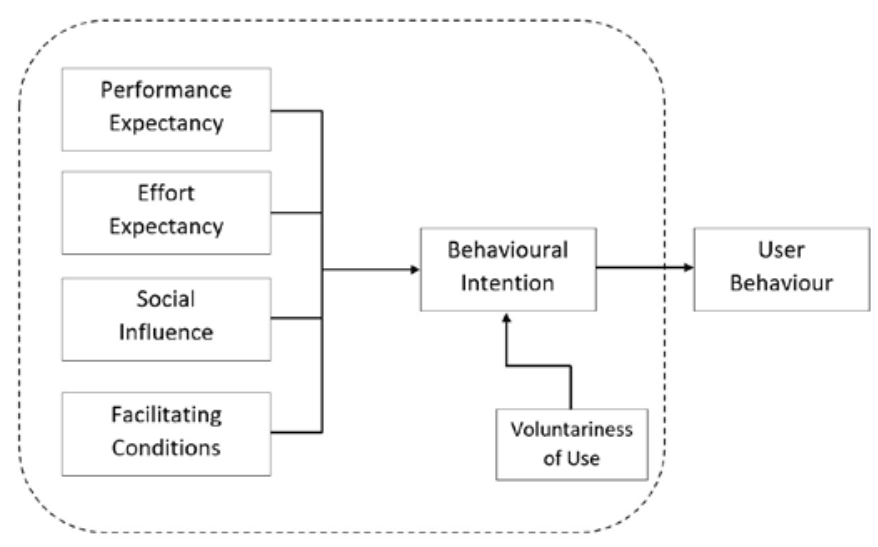

Fig. 5. User Acceptance Model Framework based on UTAUT.

In this study, one variable acted as the moderator from the UTAUT model, which was the Voluntariness of Use (VU). VU explores the extent to which an individual or an organisation believes that the acceptance or the use of new technologies happens voluntarily [45].

Hence, in this study, the VU evaluated the employee's readiness towards the collaboration team formation based on the Fuzzy-GA approach, whereby the more voluntarily a person wanted to use the proposed system, the higher the person's intention was to use the system. When automated team formation is to be implemented in an organisation, it may be a part of the requirements that the employees need to use the system. However, if they are not required to use the system, the question lies if they may still intend to use the proposed system. Therefore, the VU moderator was included in this study to find out the employees' level of voluntarism to use this proposed system. Based on the model proposed, the following hypotheses were established for this study:

- Hypothesis 1 (H1): PE has a positive effect on individual BI to use the Fuzzy-GS collaborative team formation system.

- Hypothesis 2 (H2): EE has a positive effect on individual BI to use the Fuzzy-GS collaborative team formation system.

- Hypothesis 3 (H3): SI will exert a positive influence on individual BI to use the Fuzzy-GS collaborative team formation system.

- Hypothesis 4 (H4): FC has a positive correlation with individual BI to use the Fuzzy-GS collaborative team formation system.

- Hypothesis 5 (H5): $\mathrm{VU}$ is positively related to the individual BI to use the Fuzzy-GS collaborative team formation system.

The development of hypotheses H1, H2, and H3 was supported by [46], where the constructs of PE, EE and SI were used to investigate the acceptance (BI) of the respondents to their virtual team framework in a learning environment. In [47], it was reported that the attitude towards the intention to use could be influenced by SI and FC, where FC was seen to be instrumental in empowering the individuals to have positive acceptance of the technology. Hence, this supports the hypothesis H4 tested in this study. In [45], the work had predicted the negative impact of VU on BI. However, in this study, the VU was investigated to find the positive impact on BI. The focus was to verify whether the respondents were inclined to voluntarily accept the technology.

\section{Data Collection}

Based on the UTAUT model framework in Fig. 5, a Likertscale questionnaire was used to collect data on the acceptance of IT department employees towards the proposed Fuzzy-GA approach for collaborative team formation in an organisation.

The questionnaire and the artefact for the collaborative team formation framework were distributed to the respondents, who are employees of an organisation in Penang, Malaysia. The data was used to analyse the technology acceptance by the organisation's employees. The constructions of the questions are shown in Table III.

TABLE III. THE CONSTRUCTION OF QUESTIONS

\begin{tabular}{|c|c|c|c|}
\hline Construct & Item & Questionnaire item & $\begin{array}{l}\text { Cited } \\
\text { from }\end{array}$ \\
\hline \multirow{4}{*}{$\begin{array}{l}\text { Performance } \\
\text { Expectancy }\end{array}$} & PE1 & $\begin{array}{l}\text { I would find the Fuzzy-GA collaborative } \\
\text { team formation system as useful in my } \\
\text { job. }\end{array}$ & {$[30]$} \\
\hline & PE2 & $\begin{array}{l}\text { Using Fuzzy-GA collaborative team } \\
\text { formation system will enable me to } \\
\text { accomplish my job more quickly. }\end{array}$ & \multirow{3}{*}[41]{} \\
\hline & PE3 & $\begin{array}{l}\text { Using Fuzzy-GA collaborative team } \\
\text { formation system will increase my } \\
\text { productivity. }\end{array}$ & \\
\hline & PE4 & $\begin{array}{l}\text { Using Fuzzy-GA collaborative team } \\
\text { formation system will improve my } \\
\text { performance in my job }\end{array}$ & \\
\hline \multirow{4}{*}{$\begin{array}{l}\text { Effort } \\
\text { expectancy }\end{array}$} & EE1 & $\begin{array}{l}\text { It will be easy for me to become skilful at } \\
\text { using the Fuzzy-GA collaborative team } \\
\text { formation system. }\end{array}$ & [30] \\
\hline & EE2 & $\begin{array}{l}\text { Learning how to use Fuzzy-GA } \\
\text { collaborative team formation system will } \\
\text { be easy for me. }\end{array}$ & \multirow{3}{*}{ [41] } \\
\hline & EE3 & $\begin{array}{l}\text { I understand clearly on how to use the } \\
\text { Fuzzy-GA collaborative team formation } \\
\text { system. }\end{array}$ & \\
\hline & EE4 & $\begin{array}{l}\text { I do not have any difficulties in explaining } \\
\text { why using Fuzzy-GA collaborative team } \\
\text { formation system may be beneficial. }\end{array}$ & \\
\hline \multirow{2}{*}{$\begin{array}{l}\text { Social } \\
\text { influence }\end{array}$} & SI1 & $\begin{array}{l}\text { People who influence my behavior think } \\
\text { that I should use Fuzzy-GA collaborative } \\
\text { team formation system. }\end{array}$ & \multirow{2}{*}{ [41] } \\
\hline & SI2 & $\begin{array}{l}\text { People who are important to me think that } \\
\text { I should use Fuzzy-GA collaborative team } \\
\text { formation system. }\end{array}$ & \\
\hline
\end{tabular}


(IJACSA) International Journal of Advanced Computer Science and Applications,

\begin{tabular}{|c|c|c|c|}
\hline & SI3 & $\begin{array}{l}\text { The organisation has supported to use } \\
\text { Fuzzy-GA collaborative team formation } \\
\text { system. }\end{array}$ & [30] \\
\hline \multirow{3}{*}{$\begin{array}{l}\text { Facilitating } \\
\text { conditions }\end{array}$} & FC1 & $\begin{array}{l}\text { I have the necessary resources to use } \\
\text { Fuzzy-GA collaborative team formation } \\
\text { system. }\end{array}$ & [41] \\
\hline & FC2 & $\begin{array}{l}\text { I have the necessary knowledge to use } \\
\text { Fuzzy-GA collaborative team formation } \\
\text { system. }\end{array}$ & [30] \\
\hline & FC3 & $\begin{array}{l}\text { A specific person or specific group is } \\
\text { available for assistance if there are } \\
\text { difficulties concerning the use of Fuzzy- } \\
\text { GA collaborative team formation system. }\end{array}$ & [41] \\
\hline \multirow{3}{*}{$\begin{array}{l}\text { Behavioural } \\
\text { intention }\end{array}$} & BI1 & $\begin{array}{l}\text { I intend to use Fuzzy-GA collaborative } \\
\text { team formation system in the future. }\end{array}$ & \multirow{3}{*}[41]{} \\
\hline & BI2 & $\begin{array}{l}\text { I predict that I will use Fuzzy-GA } \\
\text { collaborative team formation system in } \\
\text { the future. }\end{array}$ & \\
\hline & BI3 & $\begin{array}{l}\text { I plan to use Fuzzy-GA collaborative team } \\
\text { formation system in the future. }\end{array}$ & \\
\hline \multirow[t]{2}{*}{$\begin{array}{l}\text { Voluntariness } \\
\text { of use }\end{array}$} & VU1 & $\begin{array}{l}\text { Although it might be helpful, using } \\
\text { Fuzzy-GA collaborative team formation } \\
\text { system is certainly not compulsory for my } \\
\text { job. }\end{array}$ & [41] \\
\hline & VU2 & $\begin{array}{l}\text { My use of Fuzzy-GA collaborative team } \\
\text { formation system data is voluntary. }\end{array}$ & \\
\hline
\end{tabular}

\section{RESUlt AND DisCUSSION}

During data collection, the artefacts were presented to the respondents, and the questionnaires were answered. In this section, the results from this data collection are presented. The survey was conducted to study the user's acceptance of the proposed Fuzzy-GA collaborative team formation system. With the help of the UTAUT framework, the results projected the respondents' intention to use the proposed system as a decision support system for collaborative team formation.

\section{A. Data and Descriptive Analysis}

As mentioned in Section VI-C, the five-point Likert scale was used, representing Strongly Disagree to Strongly Agree. 70 questionnaires were administered, and a total number of 50 were returned, with a response rate of $71 \%$. The statistical tool, SPSS 24, was applied to capture and analyse the data from the questionnaire. Table IV shows the descriptive statistics for the UTAUT constructs from the response to each question. The mean values for PE, EE, SI, FC and VU were between 3 and 4, implying that most responses from the respondents were somewhat Neutral and Agree.

\section{B. Pearson's Correlation}

Pearson's Correlation was employed to define the strength of the relationship between two variables. Table $\mathrm{V}$ presents the range and categories of Pearson's Correlation coefficient strength described by [37], which was used as a benchmark of the relationship strength.

To investigate the acceptance of the proposed collaborative team formation approach, the impact of the UTAUT constructs of the independent variables, PE, EE, SI and FC towards the dependent variable, BI and the employee's readiness for the VU towards BI were evaluated. Table VI shows the result based on Pearson's Correlation analysis.
TABLE IV. DESCRIPTIVE STATISTICS

\begin{tabular}{|c|c|c|c|c|}
\hline Code & Minimum & Maximum & Mean & Std. Deviation \\
\hline \multicolumn{5}{|c|}{ Performance Expectancy (PE) } \\
\hline PE1 & 2 & 5 & 4.13 & .730 \\
\hline PE2 & 2 & 5 & 3.77 & .858 \\
\hline PE3 & 2 & 5 & 3.80 & .961 \\
\hline PE4 & 2 & 5 & 3.93 & .785 \\
\hline \multicolumn{5}{|c|}{ Effort Expectancy (EE) } \\
\hline EE1 & 3 & 5 & 4.00 & .788 \\
\hline EE2 & 2 & 5 & 4.10 & .923 \\
\hline EE3 & 2 & 5 & 3.87 & 1.137 \\
\hline EE4 & 2 & 5 & 3.67 & .994 \\
\hline \multicolumn{5}{|c|}{ Social Influence (SI) } \\
\hline SI1 & 2 & 5 & 3.47 & .819 \\
\hline SI2 & 2 & 5 & 3.57 & .858 \\
\hline SI3 & 2 & 5 & 3.90 & .803 \\
\hline \multicolumn{5}{|c|}{ Facilitating Conditions (FC) } \\
\hline FC1 & 2 & 5 & 3.80 & .805 \\
\hline FC2 & 2 & 5 & 3.93 & .785 \\
\hline FC3 & 2 & 5 & 3.50 & 1.009 \\
\hline \multicolumn{5}{|c|}{ Behavioural Intention (BI) } \\
\hline BI1 & 2 & 5 & 3.83 & .950 \\
\hline BI2 & 2 & 5 & 3.83 & .986 \\
\hline BI3 & 2 & 5 & 3.87 & .973 \\
\hline \multicolumn{5}{|c|}{ Voluntariness of Use (VU) } \\
\hline VU1 & 1 & 5 & 3.67 & 1.155 \\
\hline VU2 & 2 & 5 & 3.67 & .758 \\
\hline
\end{tabular}

TABLE V. THE RANGE AND CATEgORIES OF PEARSON'S CORRELATION COEFFICIENT STRENGTH [37]

\begin{tabular}{|l|l|}
\hline Range Value & Category of the Relationship Strength \\
\hline $0.50-1.0$ & Strong \\
\hline $0.30-0.49$ & Moderate \\
\hline $0.10-0.29$ & Weak \\
\hline
\end{tabular}

TABLE VI. PEARSON'S CORRELATION RESUlTS FOR ALL VARIABLES

\begin{tabular}{|c|c|c|c|c|c|c|}
\hline & M_PE & M_EE & M_SI & M_FC & M_BI & $M \_V U$ \\
\hline$M \_P E$ & 1 & $.739^{* *}$ & $.780^{* *}$ & $.752^{* *}$ & $.785^{* *}$ & .023 \\
\hline M_EE & $.739^{* *}$ & 1 & $.852^{* *}$ & $.879^{* *}$ & $.790^{* *}$ & .114 \\
\hline M_SI & $.780^{* *}$ & $.852^{* *}$ & 1 & $.835^{* *}$ & $.858^{* *}$ & .204 \\
\hline M_FC & $.752^{* *}$ & $.879^{* *}$ & $.835^{* *}$ & 1 & $.784^{* *}$ & .172 \\
\hline M_BI & $.785^{* *}$ & $.790^{* *}$ & $.858^{* *}$ & $.784^{* *}$ & 1 & .214 \\
\hline$M \_V U$ & .023 & .114 & .204 & .172 & .214 & 1 \\
\hline
\end{tabular}




\section{Hypothesis Evaluation}

In this section, the five proposed hypotheses are evaluated. The correlation values to validate these hypotheses can be referred to in Table VI.

Table $\mathrm{V}$ is used as the reference to determine the strength of the relationship between two variables in each hypothesis.

- Hypothesis 1: The Pearson's correlation value for mean PE (M_PE) to mean BI (M_BI) was 0.785. Thus, PE had a strong positive effect on individual BI. Hence, hypothesis $H 1$ was supported.

- Hypothesis 2: The Pearson's correlation value for mean EE (M_EE) to mean BI (M_BI) was 0.790. Thus, EE had a strong positive effect on individual BI. Hence, hypothesis $H 2$ was supported.

- Hypothesis 3: The Pearson's correlation value for mean SI (M_SI) to mean BI (M_BI) was 0.858. Thus, SI has a strong positive influence on individual BI. Hence, hypothesis $H 3$ was supported.

- Hypothesis 4: The Pearson's correlation value for mean FC (M_FC) to mean BI (M_BI) was 0.784. Thus, FC had a strong positive correlation with individual BI. Hence, hypothesis $H 4$ was supported.

- Hypothesis 5: The Pearson's correlation value for mean VU (M_VU) to mean BI (M_BI) was 0.214. Thus, VU had a weak positive correlation BI. Hence, hypothesis H5 was not supported.

\section{Discussion}

As mentioned previously, the Pearson's Correlation results for all the variables tested are shown in Table VI. The relationship of the first independent variable, Performance Expectancy (PE) to the Behavioural Intention (BI) can be interpreted from the mean $\mathrm{PE}$ to mean $\mathrm{BI}$ correlation value, where the value was 0.785 . For the next independent variable, Effort Expectancy (EE), the correlation value of mean EE (M_EE) to mean BI (M_BI) was 0.790 .

Next, the relationship of the independent variable Social Influence (SI) with BI can be referred to where the mean SI (M_SI) to mean BI (M_BI) had the correlation value of 0.858. For the last independent variable, Facilitating Conditions (FC), the correlation value of mean FC (M_FC) to mean BI (M_BI) was 0.784 .

Referring to the benchmark value shown in Table $\mathrm{V}$ and the Pearson's correlation values of the independent variables PE, $\mathrm{EE}, \mathrm{SI}$ and FC to the dependent variable BI, the values were within the range of $0.5-1.0$. This shows that there were strong relationships and positive effects between those independent variables with the BI. Therefore, the survey showed that the employees (respondents) were positive towards accepting the proposed Fuzzy-GA-based decision-making approach for collaborative team formation, where their intention to use the system was high.

Currently, limited research applied UTAUT to investigate the acceptance towards collaborative team systems. Thus, this study was motivated to investigate the level of acceptance towards a collaborative team system using the UTAUT construct, as previous researchers $[25,26]$ reported the advantage of UTAUT compared to other models such as TAM. Because of the limitations, comparisons were made with other studies that used UTAUT for acceptance towards technology in general.

The work by [46] explored acceptance towards virtual teams but focused more on the learning environment using the UTAUT. The author in [46] investigated variables PE, EE, SI and FC towards the BI. In their findings, PE, SI and FC had a positive impact on BI, which coincides with the result achieved for the same variables in this study.

However, in [46], EE did not have a positive impact on BI. On the contrary, this study found EE to have a favourable result to BI, where it had the second-highest correlation to BI. This may be due to the respondents finding that the artefact of the system seemed to be understandable and simple to be used if implemented. Thus, not much effort is required to adapt to the new system.

In [47], the researcher carried out an extensive review on the acceptance level of teachers and students on computer- and technology-based education systems. From the systems reviewed for the year 2017 to 2020 in [47], there were 16 works reviewed that used all four variables (PE, EE, SI and FC) in their studies. In that 16 works, each of the variables that had a direct or positive impact on BI were reported as such 1) PE - 15 direct impacts, 2) EE - 12 direct impacts, 3) SI - 11 direct impacts, 4) FC - 10 direct impacts, where one study had shown a very significant impact of FC compared to other variables. In this paper, the most significant variable was found to be SI.

In this study, from the strong relationship of PE to $\mathrm{BI}$, it can be deliberated that the respondents had a positive expectancy that using the proposed system, if implemented in the organisation, can somehow help their tasks be completed more efficiently and increase their productivity.

The relationship of EE to $\mathrm{BI}$ was also strong; thus, the respondents would have no problem making an effort to use the system. The correlation value of the relationship of FC to BI was slightly lower compared to the other independent variables but was still in the range of a strong relationship. Hence, this implies that the respondent believed that there would be enough facilitating resources and help when using the proposed system.

The independent variable SI had the strongest positive correlation with BI as it had the highest correlation value. This shows that employees can be influenced by their social peers and networks towards accepting the proposed collaborative team formation. This demonstrates the importance of social influence among the employees when adopting new technology within their working environment.

Although the independent variables all showed positive effects towards intention to use the proposed system that was not the case with the moderator variable, Voluntariness of use (VU). For the moderator VU, the value of Pearson's Correlation for mean VU (M_VU) to mean BI (M_BI) was 
only 0.214 . This is in the range of $0.00-0.29$, as shown in Table V, which indicates a weak relationship.

The value shows that the VU was negatively related to BI. This coincides with the result achieved by [45] that had predicted there would be a negative impact of VU towards BI. Even in the study by [48] that reported VU had a positive impact on BI and other independent variables, the VU was negatively correlated to the user behaviour.

From the findings in this study for moderator VU, the negative correlation may have occurred because the employees were not ready to voluntarily transform the manual collaborative team formation into an automated collaborative team formation. They might have the intention to use it if it was made compulsory by the organisation and also had a positive attitude in their intention to use the system, but they were not inclined towards using it voluntarily.

\section{CONCLUSION}

This research studied the user's acceptance of the proposed framework for organisational collaborative team formation by incorporating the Fuzzy-GA approach and integrating four factors that influence team formation: leadership, trust, skills and individual performance. FL was utilised to assign a detailed weight for the four team formation factors as fuzzy attributes. Then, GA was applied to optimise the fuzzy attributes. The acceptance of users to the Fuzzy-GA collaborative team formation was evaluated by using the UTAUT survey, and the results were presented.

The results from the analysis showed that the organisation's employees accept the proposed Fuzzy-GA based approach on collaboration team formation based on the positive Behavioural Intention (BI) on the Performance Expectancy (PE), Effort Expectancy (EE), Social Influence (SI) and Facilitating Conditions (FC). This shows that the employees tend to accept the use of the system if it were to be imposed on them. Thus, this proposed framework is believed to be capable of forming a high visionary workforce while improving team performance at all levels. Looking at the positive outcome from the variables PE, EE, SI and FC, in the results of the user acceptance study, this proposed study is seen to have the potential to be implemented in organisations.

However, the employees were not ready to voluntarily transform towards an effective collaborative team formation, shown from the low coefficient strength of Pearson's Correlation analysis on Voluntariness of use (VU). From this finding, although they might intend to use it if it was made compulsory or found it helpful in project completion, they might not be ready to adapt to the system voluntarily. This may be because this type of system was still new to them, and they were not familiar with it. Hence, this paper can serve as a reference for potential top management in organisations that intend to adopt a similar automated collaborative team formation to strategise a better approach to increase their employees’ voluntary involvement in such a system.

In future work, the rating component of the Fuzzy-GA collaborative team formation can be further expanded. The team members rating from the successfully formed team and implemented project can be reused. Thus, a new project requirement can be added, for example, experience in successful team formation for future team formation consideration. Besides that, the future work for the Fuzzy-GA collaborative team formation will focus on the improvement and further evaluation of the Fuzzy-GA efficiency especially on the optimisation of the group formation. The Fuzzy-GA will be considered for further enhancement by tuning the GA component of the framework. For example, the Fuzzy-GA approach can be hybridised with other metaheuristic algorithms such as simulated annealing or ant colony optimisation.

\section{ACKNOWLEDGMENT}

This research is supported by the Short-Term Grant, Universiti Sains Malaysia (304/PKOMP/6315392).

\section{REFERENCES}

[1] B. W. Tuckman, "Developmental sequence in small groups," Psychological Bulletin”, vol. 63(6), pp. 384-399, 1965.

[2] A. Belbin, "Comprehensive Review of Belbin Team Roles,” 2014. Retrieved from https://www.belbin.com/.

[3] S. W. J. Kozlowski, and B. S. Bell, "Work Groups and Teams in Organisations,” Handbook of Psychology. 2003.

[4] O. Fachrunnisa, H. K., Tjahjono, and M. Palupi, "Cognitive collective engagement in virtual collaborative team," 7th International Conference on Industrial Technology and Management (ICITM), pp. 390-393, 2018.

[5] A. A. Brennan, and J. T. Enns, "When two heads are better than one: Interactive versus independent benefits of collaborative cognition," Psychonomic Bulletin \& Review, vol. 22(4), pp. 1076-1082, 2014.

[6] B. Bahrami, K., Olsen, P. E. Latham, , A. Roepstorff, G. Rees and C. D. Frith, "Optimally interacting minds," Science, vol. 329(5995), pp. 10811085, 2010.

[7] S. K., Misra and A Ray, "Software developer selection: A holistic approach for an eclectic decision,” International Journal of Computer Applications, vol. 47(1), pp. 12-18, 2012.

[8] H. K. He, C. Li, S. Z. Lin and S. Liang, "Creating a high-performance exhibitor team: A temporary-organisation perspective," International Journal of Hospitality Management, vol. 81, pp. 21-29, 2019.

[9] M. Alsharo, D. Gregg, and R. Ramirez, "Virtual team effectiveness: The role of knowledge sharing and trust," Information \& Management, vol. 54 (4), pp. 479-490, 2017.

[10] R. Paul, J. R. Drake, and H. Liang, "Global virtual team performance: The effect of coordination effectiveness, trust, and team cohesion," IEEE Transactions on Professional Communication, vol. 59(3), pp. 186202, 2016.

[11] L. Zhang and X. Zhang, "SVM-based techniques for predicting crossfunctional team performance: Using team trust as a predictor," IEEE Transactions on Engineering Management, vol. 62(1), pp.114-121, 2015.

[12] M. Fathian, M. Saei-Shahi, and A Makui, "A new optimisation model for reliable team formation problem considering experts collaboration network,” IEEE Transactions on Engineering Management, vol. 64(4), pp.586-593, 2017.

[13] Y. Xu, Y. Wang, X. Gao, and L. Wei, "Collaborative design team formation method based on three-phase comprehensive evaluation,” The 2nd International Conference on Information Science and Engineering, pp. 1907-1910, 2010.

[14] W. H. Liu, and J. A. Cross, "A comprehensive model of project team technical performance,” International Journal of Project Management, vol.34(7), pp.1150-1166, 2016.

[15] B. Feng, Z. Z. Jiang, Z. P. Fan, and N. Fu, "A method for member selection of cross-functional teams using the individual and collaborative performances," European Journal of Operational Research, vol. 203(3), pp. 652-661, 2010.

[16] J. Wu, Y. Jiang, and J. Zhu, "Human resource allocation combined with team formation," International Conference on Computational Intelligence and Applications (ICCIA), pp. 67-71, 2016. 
[17] Y. Yu, W. Chen, and J. Yang, "Team formation in business process context," IEEE 21st International Conference on Computer Supported Cooperative Work in Design (CSCWD), pp. 73-78, 2017.

[18] J. G. Esgario, M. da Silva, I. E., and R. A. Krohling, "Application of genetic algorithms to the multiple team formation problem, Neural and Evolutionary Computing, vol. 1, arXiv:1903.03523, 2019.

[19] A. V. R. A. Pitchai, and N. Savarimuthu, "Fuzzy based quantum genetic algorithm for project team formation," International Journal of Intelligent Information Technologies, vol. 12(1), pp. 31-46, 2016.

[20] I. E. D. Silva, and R. A. Krohling, "A fuzzy sociometric approach to human resource allocation”. IEEE International Conference on Fuzzy Systems (FUZZ-IEEE), pp. 1-8, 2018.

[21] F. D. Davis, "A Technology acceptance model for empirically testing new end-user information systems: Theory and results". Massachusetts Institute of Technology. 1985.

[22] F. D. Davis, R. P. Bagozzi, P. R. Warshaw, "User acceptance of computer technology: A comparison of two theoretical models", Management Science, vol. 35 (8) pp. 982-1003, 1989.

[23] N. Marangunić, and A. Granić, "Technology acceptance model: A literature review from 1986 to 2013," Universal Access in the Information Society, vol. 14(1), pp. 81-95, 2015.

[24] Venkatesh, Morris, Davis, and Davis. "User acceptance of information technology: toward a unified view. MIS Quarterly, vol. 27(3), pp. 425, 2003.

[25] M. Alan, W. Hu, and Z. Barua, "Using the UTAUT model to determine factors affecting acceptance and use of mobile health (mHealth) services in Bangladesh Mohammad,” Journal of Studies in Social Sciences, vol. 17(2), pp. 137-172, 2018.

[26] V. Venkatesh, J. Y. L. Thong, and X. Xu, "Consumer acceptance and use of information technology: Extending the unified theory of acceptance and use of technology”. MIS Quarterly: Management Information Systems, 36(1), 2012, pp. 157-178.

[27] R. D. S. Abrahão, S. N. Moriguchi, and D. F. Andrade, "Intention of adoption of mobile payment: An analysis in the light of the Unified Theory of Acceptance and Use of Technology (UTAUT)," RAI Revista De Administração e Inovação, vol. 13(3), pp. 221-230, 2016.

[28] P. Ramírez-Correa, F. J. Rondán-Cataluña, J. Arenas-Gaitán, and F. Martín-Velicia, "Analysing the acceptation of online games in mobile devices: An application of UTAUT2," Journal of Retailing and Consumer Services, vol. 50, pp. 85-93, 2019.

[29] A. Alsyouf, and A. K. Ishak, "Understanding EHRs continuance intention to use from the perspectives of UTAUT: Practice environment moderating effect and top management support as predictor variables," International Journal of Electronic Healthcare, vol. 10(1-2), pp. 24-59, 2018.

[30] R. Howard, L. Restrepo, and C.Y. Chang, "Addressing individual perceptions: An application of the unified theory of acceptance and use of technology to building information modelling," International Journal of Project Management, vol. 35(2), pp. 107-120, 2017.

[31] J. F. Balmat, F. Lafont, R. Maifret, and N. A. Pessel, "Decision-making system to maritime risk assessment," Ocean Engineering, vol. 38(1), pp. 171-176, 2011.
[32] P. C. Dhote, "Handling ambiguous data during requirements verification using fuzzy logic," International Journal of Computer Science and Communication, vol. 2(1), pp. 105-107, 2011.

[33] M. Velasquez, and P. T. Hester, "An analysis of multi-criteria decisionmaking methods," International Journal of Operations Research, vol.10 (22), pp.56-66, 2013.

[34] A. Plerou, E. Vlamou, and V. Papadopoulos, "Fuzzy genetic algorithms: Fuzzy logic controllers and genetics algorithms," Global Journal for Research Analysis, vol. 5(11), pp.497-500, 2016.

[35] M. Alsharo, D. Gregg, and R. Ramirez, "Virtual team effectiveness: The role of knowledge sharing and trust," Information and Management, vol. 54, pp. 479-490, 2017.

[36] Y. Deng, Y. Liu, and D. Zhao, "An improved genetic algorithm with initial population strategy for symmetric TSP," Mathematical Problems in Engineering, vol. 3, pp. 1-6, 2015.

[37] U. Sekaran, and R. Bougie, (2019). Research methods for business: A skill-building approach. $8^{\text {th }}$ Edition, Wiley, 2019.

[38] T. Allahviranloo, and W. Pedrycz, "Chapter 2 - Uncertain sets" in Soft Numerical Computing in Uncertain Dynamic Systems, pp. 13-65, 2020.

[39] T. A. Izzuddin, M. A. Johari, M. Z. A. Rashid and M. H. Jali, "Smart irrigation using fuzzy logic method,” ARPN Journal of Engineering and Applied Sciences, vol. 13(2), pp. 517-522, 2018.

[40] Miloš Nikolić, Milica Šelmić, Dragana Macura, Jovana Ćalić, "Bee Colony Optimization metaheuristic for fuzzy membership functions tuning,” Expert Systems with Applications, vol. 158, 113601, 2020.

[41] A. Biswas, A. Ghosh, "Silk cocoon grading by fuzzy expert systems," Soft Computing in Textile Engineering, pp. 384-402, 2011.

[42] L. Asadzadeh, "A local search genetic algorithm for the job shop scheduling problem with intelligent agents," Computers and Industrial Engineering, vol. 85, pp.376-383, 2015.

[43] C. Capa, and G. Ulusoy, "Proactive project scheduling with a biobjective genetic algorithm in an RandD department," Proceedings of the International Conference on Industrial Engineering and Operations Management, Dubai, United Arab Emirates. pp. 966-971, 2015.

[44] Z. Liu X. LI, J. Jiang, and S. Wang, "A novel improved quantum genetic algorithm for robot coalition problem," Proceedings of the IEEE International Conference on Information and Automation, Ningbo, China. pp. 2061-2064, 2016.

[45] A. Zuiderwijk, M. Janssen, and Y. K. Dwivedi, "Acceptance and use predictors of open data technologies: Drawing upon the unified theory of acceptance and use of technology," Government Information Quarterly, vol. 32(4), pp.429-440. 2015.

[46] J. Godin, L. Leader, N. Gibson, B. Marshall, A. Poddar, and P.W. Cardon, "Virtual teamwork training: factors influencing the acceptance of collaboration technology," International Journal of Information and Communication Technology, vol. 10(1), pp. 5-23, 2017.

[47] M. L. S. Yee, and M.S. Abdullah, "A review of UTAUT and extended model as a conceptual framework in education research," Jurnal Pendidikan Sains Dan Matematik Malaysia, vol.1, 2021.

[48] R. Jayaseelan, Prasanth Koothoor, and C. Pichandy, "Technology Acceptance By Medical Doctors In India: An Analysis With UTAUT Model,” International Journal of Scientific and Technology Research vol. 9(1), pp. 3854-3857, 2020. 